\title{
The development of an improved PCR-based marker system for $S w-5$, an important TSWV resistance gene of tomato
}

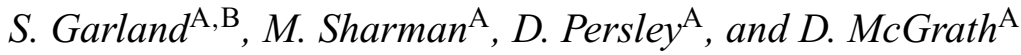

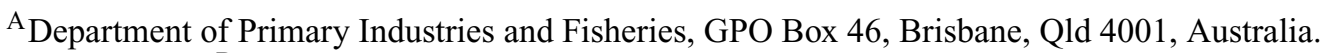 \\ ${ }^{\mathrm{B} C}$ Corresponding author. Email: Stephen.Garland@dpi.qld.gov.au
}

\begin{abstract}
S w-5$ is an important disease resistance gene of tomato, providing broad resistance to Tomato spotted wilt virus (TSWV). A cleaved amplified polymorphic sequence (CAPS) marker, closely linked to the gene, has been reported. Although the $S w-5$ locus has been characterised, a gene-specific marker has not been developed. This paper presents a PCR-based marker-system that consists of the co-amplification of a dominant marker representing the $S w-5$ gene sequence, and the modified CAPS marker as a positive control and indicator of genotype.
\end{abstract}

Additional keyword: rapid DNA extraction.

\section{Introduction}

Tomato spotted wilt virus (TSWV) (genus Tospovirus, Family Bunyaviridae) causes major losses in tomato (Lycopersicon esculentum) production throughout the world (Roselló et al. 1996). The very wide host range of TSWV among crop and weed species and the efficient transmission by western flower thrips (Frankliniella occidentalis) and other thrip species, contribute to the worldwide importance of TSWV (Prins and Goldbach 1998). Host resistance is an effective means of managing TSWV and several sources of resistance have been found in Lycopersicon species (Stevens et al. 1994). The dominant $S w-5$ gene is the most widely used source of resistance (Spassova et al. 2001). This gene was derived from L. peruvianum and introgressed into the fresh market tomato cultivar, Stevens (Stevens 1964; Thompson and van Zijl 1996).

The gene $S w-5$ is closely linked to the restriction fragment length polymorphism (RFLP) markers CT220 and CT71 and is located near the telomere of chromosome 9 (Stevens et al. 1995). $S w-5$ is a member of a loosely clustered gene family, members of which have been genetically mapped close to $S w-5$, to other regions of chromosome 9 , and to chromosome 12 (Brommonschenkel et al. 2000).

Spassova et al. (2001) characterised 2 highly homologous $S w-5$ gene candidates within $40 \mathrm{~kb}$ of CT220. The genes, tentatively named $S w-5 a$ and $S w-5 b$, are members of the coiled-coil, nucleotide-binding, leucine-rich repeat class of resistance genes. The $S w-5 b$ gene was found to be vital for resistance to TSWV in transformed tobacco plants (Spassova et al. 2001).

The $S w-5$ locus was shown to be effective against many TSWV isolates (Cho et al. 1996; Roselló et al. 1996) and to provide resistance against 2 other tospoviruses infecting tomato, Groundnut ringspot virus and Tomato chlorotic spot virus (Boiteux and Giordano 1993; Brommonschenkel et al. 2000). Spassova et al. (2001) suggested that the broad resistance may be due to the presence of $S w-5$ homologues, and those authors characterised a further 3 related genes near CT220, designated as $S w-5 c, d$, and $e$.

Folkertsma et al. (1999) developed a cleaved amplified polymorphic sequence (CAPS) marker for $S w-5$ based on CT220 sequence. However, no marker has been developed from the available gene sequence. We present a polymerase chain reaction (PCR)-based marker system that consists of a dominant marker representing the $S w-5 b$ gene sequence and incorporates the modified CAPS marker as a positive control and potential indicator of genotype (homozygous resistant $v$. heterozygote).

\section{Materials and methods}

$S w-5$ analogues (GenBank accessions $S w-5 a$ and $b$ AY007366; $S w-5 c$, $d$, and $e$ AY007367) were aligned using ClustalW (WWW Service at the European Bioinformatics Institute http://www.ebi.ac.uk/clustalw; Higgins et al. 1994) in order to identify polymorphic sections, and sequences specific to $S w-5 b$. The leucine-rich-repeat (LRR) domain was targetted for the production of $S w-5 b$ sequence-specific PCR primers. The LRR region was selected because it is a characteristic feature of the NBS (nucleotide binding site)-LRR class of disease resistance genes, and possesses high levels of polymorphism. $S w-5 a$ has been identified as the most similar analogue to $S w-5 b$ (Spassova et al. 2001), with only $2.2 \%$ of bases differing. In the LRR domain, $5.6 \%$ of bases were found to differ, whereas $1.1 \%$ of bases were different between $S w-5 a$ and $S w-5 b$ for the remainder of the gene sequence.

PCR primers were designed for a 305-bp section of the LRR domain of $S w-5 b$, using the computer program Primer3 (Rozen and Skaletsky 2000). This DNA fragment had $7.9 \%$ of bases different between 
$S w-5 b$ and $S w-5 a$. The sequence differences included a 3-bp deletion in $S w-5 a$. Primer details are provided in Table 1. Both primers were polymorphic for the $3^{\prime}$ end when compared with the $S w-5 a$ sequence. The eighth base, from the $5^{\prime}$ end of the forward primer (Sw-5b-LRR-F), and the seventh base of the reverse primer (Sw-5b-LRR-R), were also polymorphic for the same comparison. Initial testing with this primer pair indicated that specificity was obtained at a relatively low annealing temperature of $50^{\circ} \mathrm{C}$ and therefore it was not necessary to incorporate artificial mismatches near the $3^{\prime}$ end of the primers. Specificity was tested by achieving positive amplification in resistant lines and no apparent amplification from a susceptible cultivar.

Folkertsma et al. (1999) provided primer details for the CT220 fragment, a locus within $25 \mathrm{~kb}$ of $S w-5 b$, and indicated that a MseI digestion was suitable for the production of a CAPS-based marker for the identification of $S w-5$ (recognition sequence T $\mathrm{T}^{\mathbf{V}} \mathrm{TAA}$ ). MseI digestion of the product from $L$. esculentum produces a fragment equivalent to $94 \mathrm{bp}$ and 4 small fragments less than $40 \mathrm{bp}$. MseI digestion of a fragment from a resistant line (assuming linkage has been maintained) produces a fragment equivalent to $119 \mathrm{bp}$ and 4 small fragments. The $S w-5 b$ sequence contains a $M s e$ I restriction site but not the recognition sequence for AseI (AT $\left.{ }^{\boldsymbol{\nabla}} \mathrm{TAAT}\right)$. To facilitate co-amplification of the CT220 fragment and the $S w-5 b$-LRR fragment, followed by a restriction digest for genotyping of the CT220 locus, the AseI enzyme was used.

The CT220 fragment from L. esculentum (sequence ID cTOF-14J16.TH.B, Solanaceae Genomics Network http://www.sgn.cornell. edu/cgi-bin/SGN/) possessed 1 restriction site for AseI and, after digestion, would be expected to produce 1 fragment equivalent to $94 \mathrm{bp}$ and 1 equivalent to $119 \mathrm{bp}$. The 213-bp fragment from a resistant line (assuming linkage has been maintained) would not be cut by AseI. Primer details for the CT220 fragment are provided in Table 1.

\section{Mapping and virus resistance assays}

Fifty $F_{2}$ individuals from a mapping-population segregating for resistance to TSWV were genotyped by screening $F_{3}$ plants for reaction to TSWV inoculation. The same $50 \mathrm{~F}_{2}$ individuals were genotyped using the marker system to test for linkage between the marker and TSWV resistance.

The $50 \mathrm{~F}_{2}$ plants were genotyped by inoculating more than 30 (in most cases) $F_{3}$ plants per line, with TSWV isolate 1423 , originally obtained from Capsicum annuum in Queensland, Australia. The virus was propagated in tomato cv. Grosse Lisse. Inoculum was prepared by grinding symptomatic leaves with a chilled mortar and pestle with cold $0.1 \mathrm{~m}$ phosphate buffer to which $0.1 \%$ sodium sulfite had been added immediately prior to use. Diatomaceous earth (Celite) and carborundum abrasives were added to the inoculum, which was then applied to plants. Plants were inoculated when the first true leaves had emerged, approximately 20 days after planting. Plants were rinsed with water after inoculation to remove excess inoculum and abrasives. Plants were inoculated twice, several days apart, to reduce the false identification

Table 1. Primers specific to the LRR domain of the $S w-5 b$ gene and the CT220 marker

\begin{tabular}{ll}
\hline Primer name & \multicolumn{1}{c}{ Oligonucleotide sequence } \\
\hline Sw-5b-LRR-F & TCTTATATTGTGGAGTTTTTGTCG \\
Sw-5b-LRR-R & TCCACCCTATCAAATCCAAC \\
ZUP641 & AAGCCGAATTATCTGTCAAC \\
ZUP642 $^{\mathrm{A}}$ & GTTCCTGACCATTACAAAAGTAC
\end{tabular}

${ }^{\text {A }}$ Primer details for the CT220 fragment (Folkertsma et al. 1999). of resistant individuals. The cultivar Grosse Lisse was included as a susceptible control in all experiments and any apparently resistant lines were usually retested, bringing the total number of individual plants tested for these resistant lines to greater than 50 .

The inoculated plants were maintained in a glasshouse and assessed for symptoms over 4 weeks. Plants from apparently resistant $F_{2}$ lines and a selection of plants with symptoms typical of TSWV were tested by ELISA using TSWV antiserum (Bio-Rad Cat. No.51267). The tests essentially followed the supplier's protocols. Both the antibodies and conjugated antibodies were used at 1:500 in carbonate coating buffer and PBS-T, respectively. Samples of tip leaves were extracted (1/10 dilution) in PBS-T (containing 2\% PVP) and assays were carried out in polystyrene microplates (Nunc-ImmunoMaxisorp, Nalge Nunc International, Roskilde, Denmark) with reaction volumes of $100 \mu \mathrm{L}$. Overnight incubations were at $5^{\circ} \mathrm{C}$ and all other incubations were at room temperature for $2-3 \mathrm{~h}$. Absorbance values at $410 \mathrm{~nm}\left(\mathrm{~A}_{410 \mathrm{~nm}}\right)$ were measured using a Dynatech MR 7000 plate reader. Samples were considered positive when mean absorbance values exceeded twice that of appropriate healthy controls.

\section{DNA extraction}

DNA was extracted from approximately $0.03 \mathrm{~g}$ of fresh leaf tissue and ground with $1 \mathrm{~mL}$ of extraction buffer (Edwards et al. 1991) at $60^{\circ} \mathrm{C}$. The extract was added to $700 \mu \mathrm{L}$ of chloroform/isoamyl alcohol $(24: 1)$, mixed, left on ice for at least $30 \mathrm{~min}$, and centrifuged at $11200 \mathrm{rcf}$ for $3 \mathrm{~min}$. DNA was precipitated from the supernatant after adding 1 volume of isopropanol followed by $5 \mathrm{~min}$ centrifugation at full speed. The pellet was washed twice with $70 \%$ ethanol and resuspended in $100 \mu \mathrm{L}$ of Tris-EDTA (TE) buffer at $\mathrm{pH} 8$.

The marker system was also tested using a rapid DNA-extraction protocol. The DNA extraction protocol was modified from that described in the Matrix Mill Manual, Harvester Technology Inc., USA. Small discs of fresh or frozen leaf tissue were cut and contained within $0.6-\mathrm{mL}$ microcentrifuge tubes by placing a leaf between the lid and the top of the tube, and closing the lid. Then, $200 \mu \mathrm{L}$ of $0.25 \mathrm{~N} \mathrm{NaOH}$ was added to the tube. The leaf was ground in the $\mathrm{NaOH}$ solution, with a pipette tip, until the solution was a pale green colour. Fifty $\mu \mathrm{L}$ of the extract was then neutralised in $200 \mu \mathrm{L}$ of $0.17 \mathrm{M}$ Tris- $\mathrm{HCl}$ with $1 \mathrm{~mm}$ EDTA (pH 7.0) (see Fig. 3 for optimisation of the relative proportion of $\mathrm{NaOH}$ extract solution to neutralising solution).

\section{PCR}

Primers were synthesised by Proligo Pty Ltd, SCU, Lismore, NSW, Australia. PCR reactions were carried out on a Perkin Elmer, Gene Amp PCR System 9700. The reaction volume was $20 \mu \mathrm{L}$ containing $1 \times$ Roche PCR Buffer, approximately $50 \mathrm{ng}$ of genomic DNA, and $188 \mu \mathrm{M}$ dNTPs. The PCR reaction mix also included $100 \mathrm{~nm}$ of each of the 4 primers, $5.75 \mathrm{~mm}$ total $\mathrm{MgCl}_{2}$, and 0.1 units of Taq DNA Polymerase (Roche) (see Fig. 1 for magnesium titration). The temperature cycling conditions were $3 \mathrm{~min}$ at $94^{\circ} \mathrm{C}$; followed by 35 cycles of $94^{\circ} \mathrm{C}$ for $30 \mathrm{~s}, 56^{\circ} \mathrm{C}$ for $30 \mathrm{~s}$, and $72^{\circ} \mathrm{C}$ for $1 \mathrm{~min}$; with a final hold at $72^{\circ} \mathrm{C}$ for $1 \mathrm{~min}$. Ase I (NEB) digestion followed the manufacturer's instructions.

PCR conditions for the rapidly extracted DNA template were as described above except for the following differences: $2 \mu \mathrm{L}$ of the neutralised DNA extract was used as PCR template, $200 \mu \mathrm{M}$ dNTPs, $150 \mathrm{~nm}$ of each of the 4 primers, $8.25 \mathrm{~mm}$ total $\mathrm{MgCl}_{2}$, and 0.2 units of Taq DNA Polymerase (Roche).

\section{Results}

The CT220 and $S w-5 b$ fragments were found to co-amplify when using a template prepared with the Edwards et al. (1991) extraction buffer (Figs 1 and 2). Digestion of 


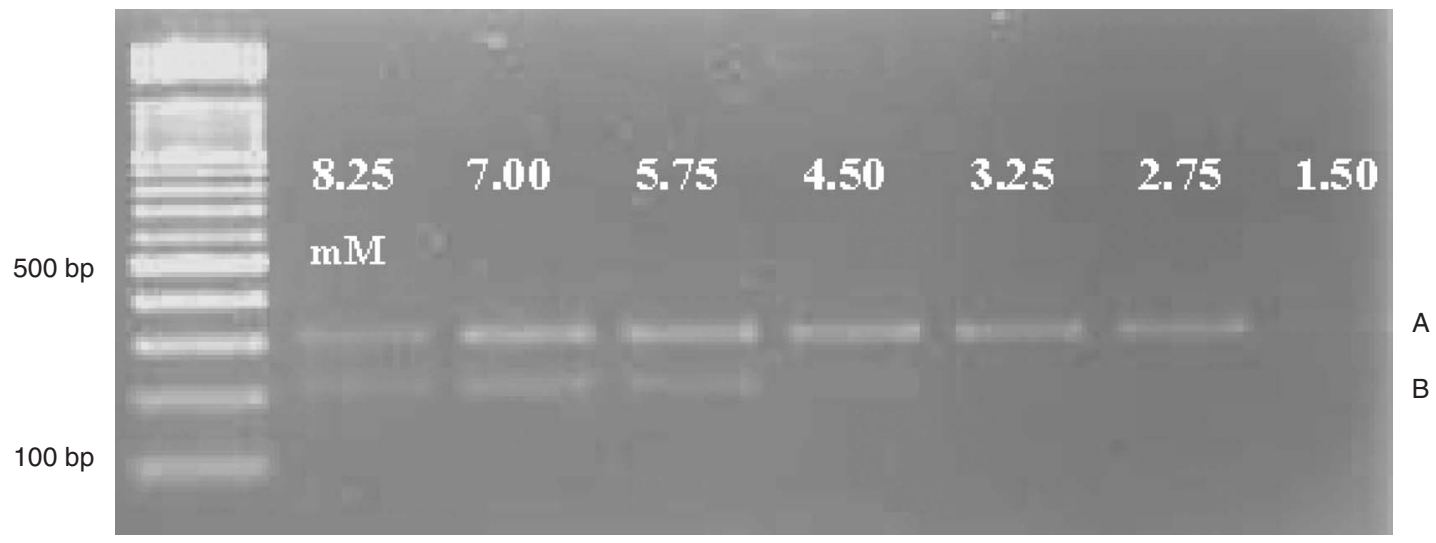

Fig. 1. Results of co-amplification of the $S w-5 b$-LRR (A) and CT220 (B) fragments at various magnesium concentrations. Concentrations (mм) are indicated. A 100-bp ladder is at the left of the gel image. PCR products are undigested. Good amplification of both products was obtained between 5.75 and $7.00 \mathrm{~mm}$. The CT220 fragment did not amplify below $4.50 \mathrm{~mm}$.

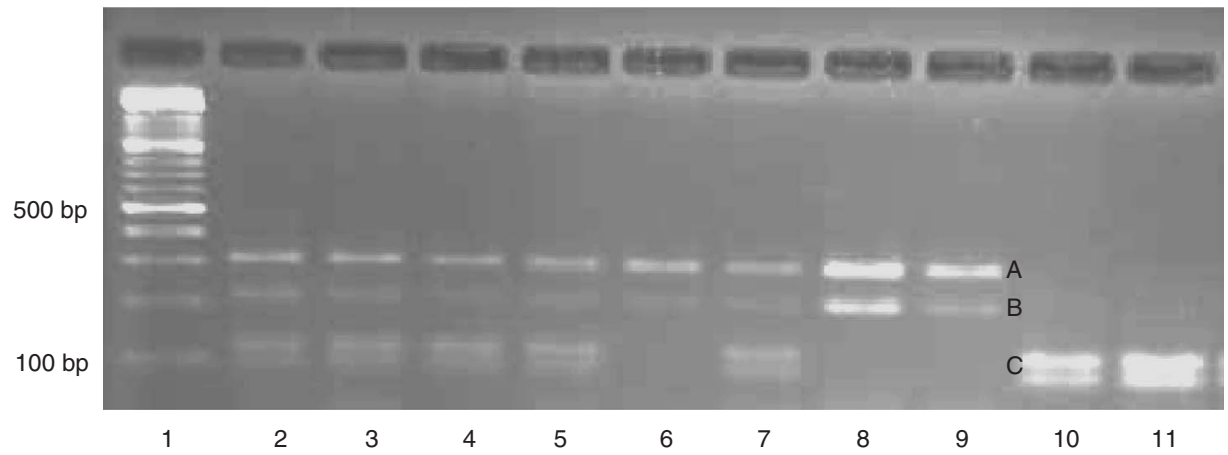

Fig. 2. Results of co-amplification of the $S w-5 b$-LRR and CT220 fragments after digestion with the AseI restriction enzyme. (A) The $S w-5 b$-LRR fragment at approximately $300 \mathrm{bp}$. (B) The uncut CT220 fragment at approximately $200 \mathrm{bp}$. (C) The 2 fragments at approximately $100 \mathrm{bp}$, produced by the AseI restriction of the CT220 fragment. (1) 100-bp ladder, $(2-5,7)$ heterozygous individuals from an $F_{2}$ population, (6) homozygous resistant individual from an $F_{2}$ population, (8-9) separate PCR amplifications for Lycopersicon esculentum accession LA3667 (known to possess Sw-5), (10) Lycopersicon pennellii LA716, (11) Lycopersicon esculentum susceptible line.

the fragments with AseI produced the expected results (Fig. 2). When the rapid extraction protocol was used, positive amplification of the marker system was also obtained (Fig. 3) and product was successfully digested using the AseI restriction enzyme (Fig. 4). However, amplification of the $S w-5 b$-LRR fragment was unreliable, alone or in combination with the CT220 fragment, when using the rapidly extracted template. Amplification of the CT220 fragment was routinely produced, alone or in combination with the $S w-5 b$-LRR fragment, when using the rapid extraction protocol.

The results of the resistance screening and genotyping of $\mathrm{F}_{2}$ individuals of the mapping population are summarised in Table 2. Ten $\mathrm{F}_{3}$ families were uniformly resistant as determined by the absence of symptoms of TSWV up to 4 weeks after inoculation, and no virus detected by ELISA. Twenty-four families segregated for resistance with an average of $24.6 \%$ of plants developing typical systemic symptoms. Sixteen families were uniformly susceptible with an average of $85.9 \%$ of plants developing severe symptoms typical of TSWV. Infection levels in the susceptible cultivar Grosse Lisse were $68-100 \%$ in all experiments.

Marker and $S w-5$ genotypes agreed for 49 of the $50 \mathrm{~F}_{2}$ plants from the mapping population. For one $\mathrm{F}_{2}$ plant the marker system indicated a heterozygous individual, and resistance screening indicated it to be homozygous susceptible. CT220 alleles were found to segregate as a single locus in an $\mathrm{F}_{2}$ mapping population as tested by $\chi^{2}(0.50$, d.f. $=2)$ analysis. The observed segregation ratio, homozygous for the $L$. peruvianum allele: heterozygous: homozygous for the L. esculentum allele, was $10: 25: 15$. Sw-5 alleles were found to segregate as a single locus in an $F_{2}$ mapping population as tested 


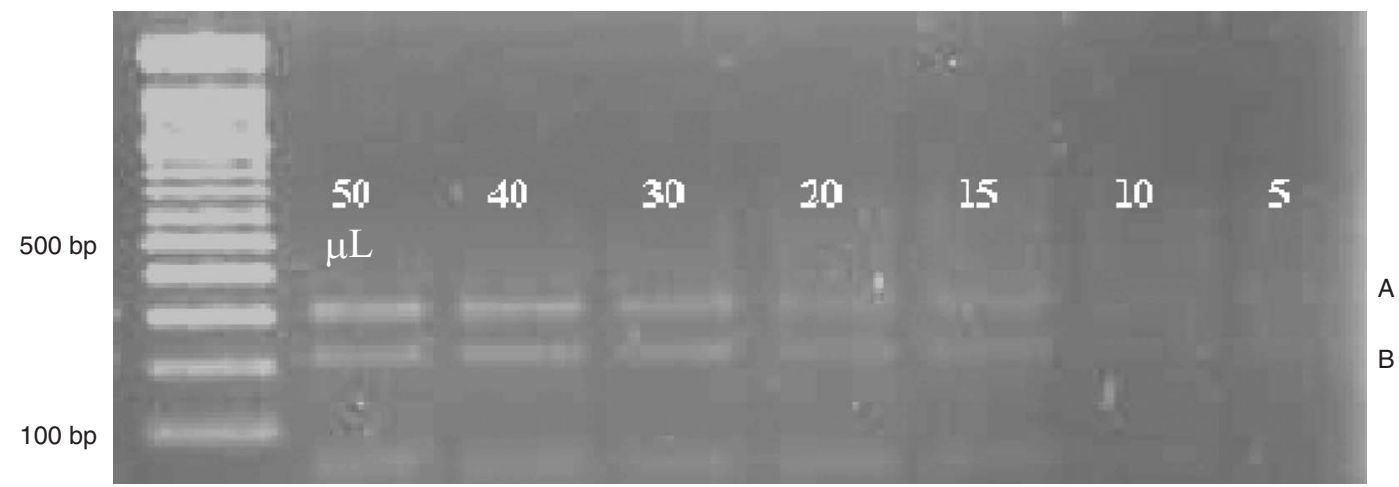

Fig. 3. Results of co-amplification of the $S w-5 b$-LRR (A) and CT220 (B) fragments, using rapidly extracted DNA templates prepared with different volumes of $\mathrm{NaOH}$ extract solution added to $200 \mu \mathrm{L}$ of neutralising solution. A 100 -bp ladder is at the left of the gel image. PCR products are undigested. Best amplification of both products was obtained when $50 \mu \mathrm{L}$ of $\mathrm{NaOH}$ solution was added. Unrelated experimentation indicated that adding $80-50 \mu \mathrm{L}$ of $\mathrm{NaOH}$ solution produced similar results. The $\mathrm{pH}$ of the extract solution ranged from 8.2 to 8.7 when $50-80 \mu \mathrm{L}$ was added. Fifty $\mu \mathrm{L}$ of $\mathrm{NaOH}$ was the maximum volume tested in order to have the $\mathrm{pH}$ of the neutralised extract solution no higher than the $\mathrm{pH}$ of the PCR buffer.

by $\chi^{2}(0.30$, d.f. $=2)$ analysis. The observed segregation ratio, homozygous resistant: heterozygous : homozygous susceptible, was $10: 24: 16$.

\section{Discussion}

The new marker system detected $S w-5$ without the need to perform a restriction digest, through the amplification

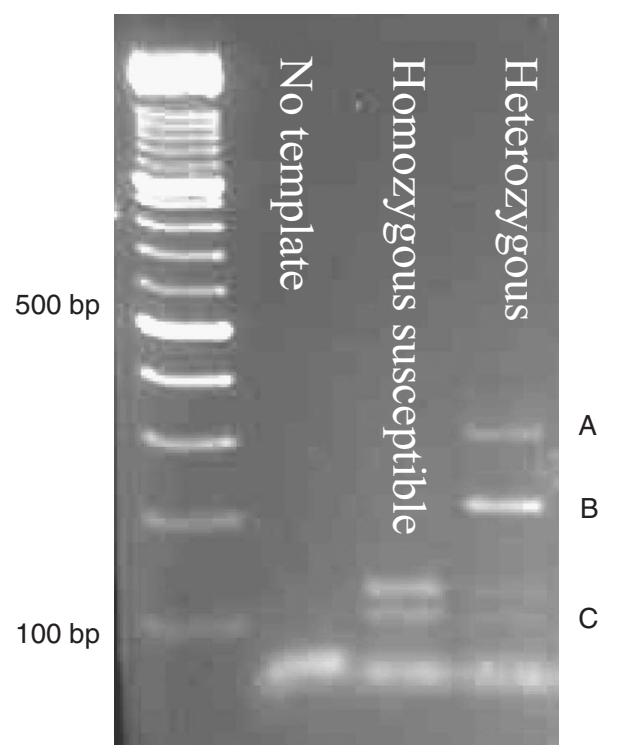

Fig. 4. Results of co-amplification of CT220 and $S w-5 b$-LRR fragments, using a rapid-extract DNA template, after digestion with the AseI restriction enzyme. A 100-bp ladder is at the left of the gel image. (A) The $S w-5 b$-LRR fragment at approximately $300 \mathrm{bp}$. (B) The uncut CT220 fragment at approximately $200 \mathrm{bp}$. (C) Two fragments at approximately $100 \mathrm{bp}$ produced by the AseI restriction of the CT220 fragment. of the $S w-5 b$-LRR fragment. The system incorporates a positive control for the PCR, in the form of the linked CT220 fragment, and therefore greatly reduces the chance of a false negative. The marker system also has the ability to predict the genotype of individuals possessing $S w-5$ (heterozygous or homozygous resistant) by performing a restriction digestion following PCR.

It should also be noted that the modification of the previously published CT220 CAPS marker, through the substitution of $\mathrm{Mse}$ I for AseI, produces a larger size difference between diagnostic bands. The MseI digestion produces a 25-bp difference and the AseI digestion creates a 94-bp difference between diagnostic bands.

The use of a rapid DNA extraction protocol would greatly increase the efficiency of the system. Unfortunately,

Table 2. Summary of results for the screening of $F_{3}$ families for resistance to TSWV

The results for $\mathrm{F}_{3}$ families are summarised for each $\mathrm{F}_{2}$ genotype (heterozygous, resistant homozygous, susceptible homozygous)

\begin{tabular}{|c|c|c|c|c|c|c|}
\hline \multirow{2}{*}{$\begin{array}{l}\text { Genotype of } F_{2} \\
\text { individuals } \\
\text { or control }\end{array}$} & \multicolumn{3}{|c|}{ Infection rate $(\%)^{\mathrm{A}}$} & \multicolumn{3}{|c|}{ No. analysed ${ }^{\mathrm{A}}$} \\
\hline & Mean & s.d. & Range & Mean & s.d. & Range \\
\hline $\begin{array}{l}\text { Heterozygotes } \\
\quad(n=24)\end{array}$ & 24.6 & 7.26 & $10.3-41.9$ & 38.4 & 8.94 & $24-68$ \\
\hline $\begin{array}{l}\text { Resistant } \\
\text { homozygotes } \\
(n=10)\end{array}$ & 0 & 0 & $0-0$ & 51.7 & 16.38 & $30-84$ \\
\hline $\begin{array}{l}\text { Susceptible } \\
\text { homozygotes } \\
(n=16)\end{array}$ & 85.9 & 9.89 & $65.2-100$ & 40.4 & 13.45 & $27-70$ \\
\hline $\begin{array}{l}\text { Susceptible control } \\
\text { cv. Grosse Lisse }\end{array}$ & 79.4 & 14.18 & $67.9-100$ & 24.0 & 14.18 & $12-30$ \\
\hline
\end{tabular}

${ }^{\mathrm{A}} \mathrm{F}_{3}$ plants per $\mathrm{F}_{2}$ individual or control plants per experiment. 
amplification of the $S w-5 b$-LRR fragment was found to be unreliable when using the rapid extraction procedure. However, the amplification of the CT220 fragment was routinely obtained using rapidly extracted DNA template. Without further optimisation, the CT220 fragment should be amplified alone, if the rapid DNA-extraction protocol is used.

Genetic mapping indicated one recombination event between the marker system and $S w-5(1 \mathrm{cM})$. For the $1 \mathrm{~F}_{2}$ individual that indicated a recombination event, the marker system identified a heterozygous individual, and resistance screening indicated it to be homozygous susceptible. The recombination event probably did not occur, and the $F_{2}$ individual actually possessed the resistance gene as indicated by the positive amplification of the putative $S w-5 b$ fragment and the heterozygous genotype of the CT220 marker, which is known to be within $25 \mathrm{~kb}$ and linked within $0.15 \mathrm{cM}$ of Sw-5 (Brommonschenkel and Tanksley 1997).

The apparent recombination is more likely to be a function of incorrect genotyping of the $S w-5$ locus through resistance screening. $S w-5$ does not produce $100 \%$ resistance $(98.7 \%$ penetrance, reviewed by Stevens et al. 1996) and is semidominant (heterozygotes are less resistant than homozygotes, reviewed by Brommonschenkel et al. 2000). It will be difficult or impossible to detect the resistance gene by screening for resistance in some cases.

\section{Acknowledgments}

This research was jointly funded by the Queensland Government's Department of Primary Industries and Fisheries (DPI\&F), Australia; Horticulture Australia Limited (Project No. VG97025, Queensland Fresh Market Tomato Breeding); and Queensland Fruit and Vegetable Growers Limited (QFVG). Thank you to Dr John Thomas and Dr Mike Smith, of DPI\&F, for kindly reviewing the manuscript.

\section{References}

Boiteux LS, Giordano L deB (1993) Genetic basis of resistance against two Tospovirus species in tomato (Lycopersicon esculentum). Euphytica 71, 151-154. doi: 10.1007/BF00023478

Brommonschenkel SH, Frary A, Tanksley SD (2000) The broad-spectrum tospovirus resistance gene $S w-5$ of tomato is a homolog of the root-knot nematode resistance gene Mi. Molecular Plant-Microbe Interactions 13, 1130-1138.

Brommonschenkel SH, Tanksley SD (1997) Map-based cloning of the tomato genomic region that spans the $S w-5$ tospovirus resistance gene in tomato. Molecular and General Genetics 256, 121-126. doi: $10.1007 / \mathrm{s} 004380050553$
Cho JJ, Custer DM, Brommonschenkel SH, Tanksley SD (1996) Conventional breeding: host-plant resistance and the use of molecular markers to develop resistance to Tomato Spot Wilt Virus in vegetables. Acta Horticulturae 431, 367-378.

Edwards K, Johnstone C, Thompson C (1991) A simple and rapid method for the preparation of plant genomic DNA for PCR analysis. Nucleic Acids Research 19, 1349.

Folkertsma RT, Spassova MI, Prins M, Stevens MR, Hille J, Goldbach RW (1999) Construction of a bacterial artificial chromosome (BAC) library of Lycospersicon esculentum cv. Stevens and its application to physically map the $S w-5$ locus. Molecular Breeding 5, 197-207. doi: 10.1023/A:1009650424891

Higgins D, Thompson J, Gibson T, Thompson JD, Higgins DG, Gibson TJ (1994) CLUSTAL W: improving the sensitivity of progressive multiple sequence alignment through sequence weighting, position-specific gap penalties and weight matrix choice. Nucleic Acids Research 22, 4673-4680.

Prins M, Goldbach R (1998) The emerging problem of tospovirus infection and nonconventional methods of control. Trends in Microbiology 6, 31-35. doi: 10.1016/S0966-842X(97)01173-6

Roselló S, Díez MJ, Nuez F (1996) Viral diseases causing the greatest economic losses to the tomato crop. I. The tomato spotted wilt virus - a review. Scientia Horticulturae 67, 117-150. doi: 10.1016/S0304-4238(96)00946-6

Rozen S, Skaletsky HJ (2000) Primer3 on the WWW for general users and for biologist programmers. In 'Bioinformatics methods and protocols: methods in molecular biology'. (Eds S Krawetz, S Misener) pp. 365-386. (Humana Press: Totowa, NJ)

Spassova MI, Prins TW, Folkertsma RT, Klein-Lankhorst RM, Hille J, Goldbach RW, Prins M (2001) The tomato gene $S w-5$ is a member of the coiled coil, nucleotide binding, leucine-rich repeat class of plant resistance genes and confers resistance to TSWV in tobacco. Molecular Breeding 7, 151-161. doi: 10.1023/A:1011363119763

Stevens JM (1964) Tomato breeding. Technical Services, Department of Agriculture, Project Rpt W-Vvl, Republic of South Africa.

Stevens MR, Heiny DK, Rhoads DD, Griffiths PD, Scott JW (1996) A linkage map of the tomato spotted wilt virus resistance gene Sw-5 using near isogenic lines and an interspecific cross. Acta Horticulturae 431, 385-392.

Stevens MR, Lamb EM, Rhoads DD (1995) Mapping the $S w-5$ locus for tomato spotted wilt virus resistance in tomatoes using RAPD and RFLP analysis. Theoretical and Applied Genetics 90, 451-456. doi: 10.1007/BF00221989

Stevens MR, Scott SJ, Gergerich RC (1994) Evaluation of seven Lycopersicon species for resistance to tomato spotted wilt virus (TSWV). Euphytica 80, 79-84. doi: 10.1007/BF00039301

Thompson GJ, van Zijl JJB (1996) Control of tomato spotted wilt virus in tomatoes in South Africa. Acta Horticulturae 431, 379-384.

Manuscript received 21 June 2004, accepted 27 January 2005 